\title{
Fernando Pessoa e a arte de jazer a vida
}

\section{Fernando Pessoa and the art to lie in life}

\section{Maria João Mayer Branco}

Universidade Nova de Lisboa/Instituto de Filosofia da Linguagem Lisboa - Portugal, e-mail: maria_joao_branco@yahoo.com

\section{Resumo}

Neste estudo procura-se avaliar as consequências da crise das categorias modernas de sujeito e consciência na poesia pessoana. Mostra-se que essa crise não conduz, em Pessoa, a uma concepção niilista da existência, e que do mal-estar do excesso de consciência nasce, na sua obra, a concepção de uma singular experiência de vitalidade em estados que o poeta identifica com a infância e com experiências-limite do tempo e do espaço. O reverso positivo da explosão da consciência não corresponde, em Pessoa, a um anseio místico de retorno à unidade e à quietude, mas a uma experiência afectiva do movimento anímico a que chama "desassossego". Irredutível às categorias filosóficas do espaço e do tempo, impossível de deter pelo pensamento, o que está em jogo é a experiência do fluxo da vida na possibilidade de "mudar de alma" ou do "saber ver" ensinado por Alberto Caeiro.

Palavras-chave: Modernidade. Sujeito. Infância. Limite. Tempo. 


\section{Abstract}

This study considers the consequences of the crisis of the modern concepts of subject and consciousness in Fernando Pessoa's poetry. Such crisis does not lead to a nihilistic conception of existence in his work but rather to a peculiar experience of vitality. The poet identifies this experience with childhood and with states where the categories of time and space reach their limits. The positive side of the explosion of consciousness is not equivalent, in Pessoa's poems, to a mystical longing for a return to unity and quietness but to an affective experience of the movement of the soul called "disquiet". In the possibilities of "changing of soul" or "know how to see" (Alberto Caeiro) what is at stake is the experience of the flow of life which is irreducible to the philosophical categories of space and time and impossible to fix within abstract thinking.

Keywords: Modernity. Subjectivity. Childhood. Limit. Time.

\section{"O mais antigo imposto à inteligência"}

Pessoa é certamente um poeta maior da expressão do mal-estar que contaminou o pensamento ocidental moderno decorrente da crise sofrida pelo conceito de sujeito e da consequente problemática da identidade. Num mundo que questiona as suas próprias garantias metafísicas, perdendo assim a âncora que a categoria da unidade lhe forneceu durante séculos, o sujeito sente também em si a desagregação dos seus limites e sofre de um modo inédito uma ruptura interior que o condena a ser "um doido que estranha sua própria alma”, como é dito no poema Hora Absurda (PESSOA, 1992, p. 24). Este eu que é outro, que sofre com a não coincidência de si consigo, com a cisão irremediável da moderna "explosão da consciência" (PESSOA, 1992, p. 24), está, nas palavras de Pessoa, condenado a "assistir à sua própria passagem" (PESSOA, 1993, p. 48), a ser espectador, estrangeiro a si próprio: "De quem é o olhar/ Que espreita por meus olhos?/ Quando penso que vejo,/ Quem continua vendo/ Enquanto estou pensando?" (PESSOA, 1992, p. 64). Nestas perguntas se condensa a estranheza que tomou as mais variadas expressões de angústia, sofrimento, suspeição, em filósofos como Pascal ou Kierkegaard, e em poetas como Rimbaud, Hofmannsthal, Rainer Maria Rilke ou Mário de Sá-Carneiro. Mas a perda da unidade da consciência, da pertença de si a si, 
alastrou, na verdade, e trouxe o sentimento da perda não apenas do laço que unia o homem ao mundo (pois todas as coisas aparecem agora afectadas pela mesma crise de identidade, pelo que não existe verdadeiramente nada que seja uno e idêntico a si mesmo, e com o qual o humano possa estabelecer uma relação), mas sobretudo a perda da noção de uma realidade fixa, una e estável, em geral. Assim, não é, portanto, apenas o sujeito, mas a totalidade do mundo que fica infectada de irrealidade (LOURENÇO, 2002, p. 159-166).

As consequências disto no universo pessoano têm uma singularidade que nunca é demais sublinhar, e neste breve ensaio procuraremos concentrar em parte delas a nossa atenção. No contexto geral de crise que foi aqui sumariamente esboçado, uma crise de esvaziamento de sentido e uma crise de valores com variadas expressões niilistas, a negação do eu não implica, em Pessoa, uma negação da vida: a sua poesia não é uma poesia do não-ser, uma apologia do nada (GIL, 1988). O caso em que esta tese é, porventura, mais difícil de provar consiste certamente no conjunto de poemas intitulado Fausto (PESSOA, 1988). A "dolorosa consciência vazia de mim próprio", "o abismo entre meu ser e mim", faz Fausto sentir que "sufoca em alma”, quer dizer, nele a consciência, o pensamento, interpõe-se sempre dividindo o sujeito de si mesmo e do mundo que o rodeia, e propagando a estranheza de tudo a tudo, impedindo o reconhecimento, a adesão sem atrito, a proximidade e a ligação com e entre as coisas. "Tudo transcende tudo;/ Intimamente longe de si mesmo,/ E infinitamente, o universo/ A si mesmo, existindo, se ilude”. Perante a transcendência de tudo a tudo, Fausto sente a impotência do pensamento em compreender o que existe: “O que é haver haver? Porque é que o que é/ É isto que é? Como é que o mundo é mundo?/ Ah, horror de pensar, como que súbito/ Desconhecer onde estou". Não por acaso, este conjunto de poemas tem como subtítulo "Tragédia Subjectiva". Trata-se ali das consequências de um excesso sofridas pelo protagonista, da tragédia de uma consciência excessiva, obsessiva, de um pensamento despótico, de uma compulsão para a análise, para a racionalização desmedida que impede aquilo a que chama "inconsciência":

Não é o vício/ Nem a experiência que desflora a alma:/ É só pensamento. Há inocência em Nero e em Tibério louco/ Porque há inconsciência. Só pensar/ Desflora até ao íntimo do ser./ Este perpétuo analisar de tudo,/ Este buscar duma nudez suprema/ Raciocinada coerentemente,/ É que tira a inocência verdadeira/ Pela suprema consciência funda/ De si, do mundo, de todos. [...] Pensar, pensar e não poder viver!/ Pensar, sempre pensar, perenemente,/ Sem poder ter mão nele! (PESSOA, 1988, p. 68). 
Vítima de um pensamento cuja imposição parece não conhecer limites e assolado pelo horror da incompreensão de um universo em que tudo está desligado de tudo ("Mas que liga espaço, tempo, que liga seres, / Que liga um mundo, cores, sons,/ Movimentos, mudanças/ Que liga qualquer cousa, sim que a liga?'), Fausto sofre por não poder deter a desmesura da obsessão analítica que o impede de aderir simplesmente ao fluxo da vida, que o impede de viver, de sentir, de amar, vendo por todo o lado o horror do mistério de haver ser e padecendo da incapacidade de comunicar com as coisas:

Suma-se-me a vida/ E a consciência e eu deixe de pensar/ De fitar o mistério e sem querer/ Compreender-lhe o horror [...] O terror desvaria-me, o terror/ De me sentir vivo e ter o mundo/ Fechado a laços de compreensão (PESSOA, 1988, p. 21).

E, no entanto, Fausto não é um niilista. Se a sua situação trágica o leva a caluniar a existência, isso apenas acontece porque a sua experiência é a de um desequilíbrio entre viver e pensar, entre existir e ser consciente. É essa a origem do seu desgosto, do horror, do tédio imenso e intenso. Ou seja, não é da vida que Fausto deseja libertar-se, mas da forma trágica de existir onde viver equivale a pensar. Por isso, o que Fausto teme verdadeiramente é a morte, o "pavoroso contrário do bulício/ E movimentação da vida vã”, o fim do movimento, o nada, a imobilidade total a que chama "monotonia":

A vida é má e o pensamento é mau,/ Mas eu temo com mudo e íntimo horror/ A morte, pois concebo-lhe como essência,/ Olhando-a do movimento da vida, / Uma monotonia não sei qual, Cujo pressentimento desvaria/ O meu incoerente pensamento.

Fausto quer, portanto, viver. Mais do que isso, Fausto sabe (Pessoa sabia) exactamente qual é a vida que tem mais valor, a vida que é mais desejável e da qual está privado pelo excesso de consciência. Esse saber liga-o tanto ao restante universo pessoano, como a tragédia subjectiva que protagoniza, acerca da qual também escreveu Bernardo Soares: "A consciência da inconsciência da vida é o mais antigo imposto à inteligência” (PESSOA, 1990, p. 41). O "horrível ser que é haver ser" e o "abismo de a existência de tudo ser um abismo,/ Ser um abismo por simplesmente ser", descreveu-o igualmente Álvaro de Campos, que, porém, no mesmo poema, diz também que 
por mais consciência que eu tenha, tudo é inconsciência/ Salvo o ter criado tudo, e o ter criado tudo ainda é inconsciência,/ Porque é preciso existir para se criar tudo,/ E existir é ser inconsciente, porque existir é ser possível haver ser,/ E ser possível haver ser é maior que todos os Deuses (CAMPOS, 2002, p. 286).

Toda a poesia de Fernando Pessoa é, em grande medida, a apologia de uma paradoxal modalidade da experiência, a inconsciência que se alcança pela disciplina de uma "atenção intensa e desatenta" (Campos sobre Caeiro $^{1}$ ), que se liga menos a uma expressão de pessimismo existencial (como diz Soares, "Eu não sou pessimista, sou triste" ${ }^{\text {"2 }}$ do que à promoção de uma singular vitalidade, de acordo com o que tentaremos mostrar. A tragédia de Fausto é, portanto, não poder sentir por tanto pensar ("Quem sente chora, mas quem pensa não"), e Fausto quer sentir. Quer dizer, o que deseja é uma vida onde a consciência não toma conta da totalidade da experiência humana, duplicando o sujeito e obrigando tudo a transcender-se sem limites, transformando o mundo num inferno onde tudo é estranho a tudo, onde tudo está separado, e no qual não há possibilidade de afecção e de sensação. Para designar o tipo de vida desejável de ser vivida, Fausto refere-se a experiências que são decisivas em todo o universo pessoano, e cuja importância fundadora procuraremos mostrar a seguir:

[...] a inocência bela do viver, / De sentir [...]/ Sentir um sentir que abertamente/ Se não ache vazio. [...] essa pureza/ Que faz a vida leve mesmo ao mais/ Sério, que nunca nos de todo afasta/ Da criança em nós, essa simplicidade/ Perdi-a e só me resta um vácuo imenso/ Que o pensamento friamente ocupa (PESSOA, 1988, p. 69).

Simplicidade, leveza, infância, palavras a que tem de se juntar a inconsciência, condições de possibilidade de um tipo de experiência que a obra de Pessoa procura retratar. Trata-se de alcançar este estado, não tanto por privação (do pensamento, da consciência, da análise), mas por uma intensificação da experiência que implica levar aos seus limites a grelha abstracta do pensamento que divide sujeito e objecto, que interrompe a continuidade da

1 CAMPOS (1997, p. 48)

2 PESSOA (1990-1991, p. 192 v. I) 
vida que liga todas as coisas e paraliza o fluxo vital inconsciente em categorias estáticas, mortas: "A Decadência é a perda total da inconsciência, porque a inconsciência é o fundamento da vida. O coração, se pudesse pensar, pararia" (PESSOA, 1990-1991, p. 19, v. II).

\section{"Há sem dúvida quem ame o Infinito"}

A crise do sujeito enquadra-se no esforço moderno de testar os limites da racionalidade e da experiência. A morte de Deus é uma imagem, senão uma consequência, desse teste, e arrastou consigo o questionamento das categorias filosóficas de tempo, espaço e causalidade. O sujeito moderno não apenas padece do estilhaçamento da sua unidade, como também se encontra tomado pela obsessão com a ideia de um Infinito inabarcável pelo exercício do pensamento, que é a ideia de uma realidade não categorizável e, portanto, incompreensível. A noção de Infinito aparece na obra de Pessoa, e defendeuse que nela se trata de uma infinitude que é mais temporal do que espacial, na medida em que o sentimento pessoano de irrealidade suscitado pelo jogo de espelhos entre o eu que sente e o eu que pensa o que sente pertence à categoria do tempo (LOURENÇO, 2002, p. 207-223). Parece-nos, porém, que a categoria do tempo não esgota o labirinto pessoano e não resolve um enigma que é de ordem poética e não filosófica (embora se possa falar de um "pensamento" em Fernando Pessoa). Por outro lado, a imagem do jogo de espelhos não é temporal, mas espacial, e coloca-nos imediatamente no coração da experiência fundamental desta obra, que é uma experiência visual. É a experiência do espectador permanente, da pulsão de ver (e de se ver) onde se incluem a ciência de Caeiro, a lucidez de Campos, as paisagens interiores de Bernardo Soares, os sonhos do Pessoa ortónimo, o "não poder tirar de mim os olhos" que horroriza Fausto. Ora, a visão liga-se intimamente com o espaço e com a sua infinita divisibilidade, ela atenta nos contornos, analisa e requer afastamento, distância daquilo que se observa. Para ver é preciso ser estranho ao visto, ser estrangeiro, diferente, e aqui se condensa o problema originário da poesia de Pessoa. A este problema acresce o de que, de acordo com a divisibilidade infinita ou infinita remissão dos limites espaciais para fora de si próprios, a visão clara de uma coisa remete para outra e essa remissão faz perder justamente a coisa que se vê. Nesse sentido, estaríamos no coração do abismo de tudo remeter para outra coisa, mencionado anteriomente, ao qual dissemos, porém, não se poder reduzir o universo pessoano. Em rigor, a obra de Pessoa procura 
uma alternativa a esse abismo, um reverso positivo da angústia da infinitude do universo. E se o espaço parece adequar-se melhor ao sentido da visão do que a categoria do tempo, importa esclarecer de que visão se trata verdadeiramente aqui, como se relaciona ela com o conceito de Infinito e que tipo de Infinito é este, afinal.

O relato de uma conversa entre Álvaro de Campos e Alberto Caeiro fornece-nos algumas pistas (CAMPOS, 1997, p. 42-44). Caeiro recusa a ideia da infinitude do espaço, defendendo que só existe o que tem limites

O que não tem limites não existe. Existir é haver outra coisa qualquer, e portanto cada coisa ser limitada. O que é que custa conceber que uma coisa é uma coisa, e não está sempre a ser uma outra coisa que está mais adiante?

Para Caeiro, diz Campos, o infinito era um "inconceito", e falando com o seu mestre o engenheiro sente "que estava discutindo, não com outro homem, mas com outro universo". O que nos interessa sublinhar é que, aparentemente, o demasiado moderno discípulo procurou seguir a lição do mestre, ou melhor, que o infinito a que se refere nos seus poemas não é verdadeiramente o objecto das suas odes. O ponto essencial não é que Campos ame o infinito, mas que ele ama de modo infinito. A infinitude abissal de um universo onde o sujeito moderno se abisma, des-substancializando-se e contaminando a existência das mais diversas modalidades de tédio e de uma total ausência de sentido (pense-se, por exemplo, no spleen de Baudelaire ou no pessimismo de um Leopardi), não é a de Álvaro de Campos, que, pelo contrário, e certamente por influência de seu mestre Caeiro, sabe que supor um espaço implica que "para além desse espaço há mais espaço, para além desse mais, e depois mais, e mais, e mais... Não acaba...", mas deseja trazer essa infinitude abstracta, teórica, analítica, para um plano concreto, que é um plano afectivo e que tem por objecto as coisas limitadas, o finito:

Há sem dúvida quem ame o Infinito,/ Há sem dúvida quem não queira nada -/ Três tipos de idealistas, e eu nenhum deles:/ Porque eu amo infinitamente o finito,/ Porque eu desejo impossivelmente o possível,/ Porque quero tudo, ou um pouco mais, se puder ser,/ Ou até se não puder ser.../ E o resultado? [...] Para mim só um grande, um profundo,/ E, ah com que felicidade infecundo, cansaço,/ Um supremíssimo cansaço,/ íssimo, íssimo, íssimo (CAMPOS, 2002, p. 523-524). 
Nestes versos se condensa o famoso projecto poético de "sentir tudo de todas as maneiras" de que o poema A passagem das horas é o insuperável registo. A exaustão que este sentir provoca é o preço de um excesso, não de consciência, mas de desejo, de amor pelo mundo "Tenho desejo forte, / E o meu desejo, porque é forte, entra na substância do mundo" (CAMPOS, 2002, p. 261). É verdade que Campos cai na tentação niilista, mas porque leva ao limite a sua capacidade de sentir, a sua simpatia por tudo o que existe:

Não sei se a vida é pouco ou de mais para mim. Não sei se sinto de mais ou de menos, não sei/ [...] Seja o que for, era melhor não ter nascido,/ Porque, de tão interessante que é a todos os momentos, / A vida chega a doer, a enjoar, a cortar, a ranger,/ A dar vontade de dar gritos, de dar pulos, de ficar no chão, de sair/ Para fora de todas as casas, de todas as lógicas e de todas as sacadas, / E ir ser selvagem para a morte entre árvores e esquecimentos/ Entre tombos, e perigos e ausência de amanhãs/ [...] Que há-de ser de mim? Que há-de ser de mim? (CAMPOS, 1997, p. 206-207).

A este momento de desespero, segue-se, porém, a conclusão: “cai a noite, a vida substitui-se./ Seja de que maneira for, é preciso continuar a viver." E começa, então, a lírica ode à noite que tira o mundo ao mundo:

Torna-me humano, ó noite, torna-me fraterno e solícito./ Só humanitariamente é que se pode viver./ [...] Só assim, ó noite, e eu nunca poderei ser assim!/ [...] Vem, ó noite, e apaga-me, vem e afoga-me em ti./ [...][ Tu que tiras o mundo ao mundo, tu que és a paz,/ Tu que não existes, que és só a ausência da luz,/ Tu que não és uma coisa, um lugar, uma essência, uma vida (CAMPOS, 1997, p. 208-209).

Falou-se da noite na poesia de Pessoa, em especial na de Álvaro de Campos, como o reverso positivo do infinito negativo (LOURENÇO, 2002, p. 207-223), ou seja, como um infinito que consola, cuja obscuridade dissolve os contornos das coisas, os limites do sujeito e a separação entre eu e mundo. E, no entanto, essa noite romântica, órfica até, a noite materna que é o ventre criador de todo o universo e o regaço aonde tudo vem repousar, convém e não convém ao poeta. A inquietação pessoana não é um exílio nostálgico das origens, um anseio místico de Unidade, porque a errância da alma é provocada, ela é mesmo desejada pelo poeta (e até, como se defendeu já, não a sua doença, mas a terapia, a cura que inventou para escapar 
à loucura ${ }^{3}$ ). Não se trata tanto de que a alma procura consolo e repouso na noite que tudo dissolve como de afirmar justamente a sua condição móvel, de afirmar que ela não é fixa, estável, porque está viva. A alma (o sujeito) só existe em movimento, ela é movimento, viagem, deambulação, nem espaço, nem tempo. Categorias filosóficas, categorias do pensamento e da consciência, o espaço e o tempo não esgotam, não podem resolver a poesia de Pessoa (nem nenhuma poesia), tal como não esgotam nenhum tipo de experiência vivida. E a obra de Pessoa apresenta justamente os limites do pensamento, os "inconceitos", a derrota da consciência e das suas categorias no confronto com a vida que vence sempre o esforço daquele que a pensa, pois é sempre (infinitamente) maior e mais rica do que qualquer conceito. É por isso que o esforço de a pensar traz insatisfação ao ortónimo, horror a Fausto, cansaço a Campos, tédio a Bernardo Soares:

Viver a vida em Extremo significa vivê-la até ao limite [...] Pode viver-se a vida em extremo pela posse dela, pela viagem ulisseia através de todas as sensações vividas, através de todas as formas de energia exteriorizada. Raros são, porém, [...] os que podem fechar os olhos cheios do cansaço soma de todos os cansaços, os que possuíram tudo de todas as maneiras. [...] a vida, tão difícil de possuir completa, e tão triste de possuir parcial (PESSOA, 1990-1991, p. 213, v. I).

Em rigor, Campos não procura na noite a unidade, porque a sua estratégia para vencer o horror do infinito é análoga à própria estratégia pessoana do processo de heteronímia, ou seja, uma estratégia de multiplicidade. Se o problema de Fausto era incapacidade de sentir, Campos vai procurar resolvêlo, não no "pavoroso contrário do bulício" que a vida é, na imobilidade nocturna e uniforme que tira o mundo do mundo, mas num transbordar de si para tudo o que há, fazendo explodir de vez a categoria da unidade a partir do desejo de sentir tudo, que não é anulação, mas afirmação de vida: "Multipliqueime para me sentir, / Para me sentir, precisei sentir tudo, / Transbordei, não fiz senão extravasar-me, / Despi-me e entreguei-me, / E há em cada canto da minha alma um altar a um deus diferente" (CAMPOS, 2002, p. 198) Os textos de Pessoa não cantam, portanto, só o fracasso e a angústia demasiado humanas e demasiado modernas; neles, a vida é posta a nu na sua inesgotabilidade, que é também por vezes a sua insuportabilidade. O desassossego

3 GIL, 1993, p. 13. 
pessoano é tanto inquietação quanto o próprio movimento da vida não pensa$\mathrm{da}^{4}$ (impensável), ausência de sossego, isto é, ausência de repouso, "tédio que não dorme" (PESSOA, 1993, p. 30). O desassossego é o próprio estar vivo, a manifestação da vida viva, a recusa da fixação (da morte), o fluxo da corrente imparável, não detida pelo pensamento, nem pelo espaço, nem pelo tempo. Nesta experiência da multiplicidade, que é a de querer sentir tudo de todas as maneiras e que implica sair da maneira espácio-temporal que é nossa, ${ }^{5}$ tratase do que é expresso no oxímoro que fala de ser "unificadamente diverso", propondo uma nova espécie de modalidade humana ao abolir poeticamente os limites da razão por analogia com a própria condição de Deus:

Afinal, a melhor maneira de viajar é sentir./ Sentir tudo de todas as maneiras./ [...] Quanto mais eu sinta, quanto mais eu sinta como várias pessoas,/ Quanto mais personalidades eu tiver,/ [...] Quanto mais unificadamente diverso, dispersamente atento,/ Estiver, sentir, for,/ Mais possuirei a existência total do universo, / Mais completo serei pelo espaço inteiro fora/ Mais análogo serei a Deus, seja ele quem for (CAMPOS, 2002, p. 251).

\section{"Dá-me outra vez a infância e leva Deus contigo"}

Como foi notado, é em Alberto Caeiro que o reverso positivo da experiência de Infinito adquire uma forma poética inexcedível (GIL, 1993; LOURENÇO, 2002), e Caeiro é o mestre do ver. ${ }^{6}$ A sua relação com a realidade é a de um "animal humano" que dispensa o pensar: nele, ver é ser a coisa vista na singularidade que lhe é própria, aquém de todas as categorias abstractas que constituem e constroem a percepção do mundo tal como o faz o sujeito transcendental kantiano.

Quero as cousas que existem, não o tempo que as mede./ [...] Não quero incluir o tempo no meu esquema./ Não quero pensar nas cousas como presentes; quero pensar nelas como cousas./ Não quero separá-las de si próprias/ [...] Eu devia vê-las, apenas vê-las;/ Vê-las até não poder pensar nelas,/

4 GIL, 1993, p. 27-28.

5 Não será demais sublinhar que se trata aqui de uma experiência poética, daquilo a que se chamou o "esquematismo poético" de Pessoa (GIL, 1993, p. 81).

${ }^{6}$ GIL, 1999, p. 15-42.

7 CAEIRO, 2001. 
Vê-las sem tempo, nem espaço,/ Ver podendo dispensar tudo menos o que se vê./ É esta a ciência de ver, que não é nenhuma (CAEIRO, 2001, p. 169).

A visão de Caeiro implica uma relação des-subjectivada com as coisas, um ver até não poder pensar, um ser a coisa vista que não separa a coisa de si mesma. Isto vale também para a relação do sujeito consigo: "Não sei o que é conhecer-me. Não vejo para dentro. Não acredito que eu exista por detrás de mim" (CAEIRO, 2001, p. 164) Esta última frase parece resolver todas as aporias da poesia de Pessoa, nomeadamente o problema da não coincidência entre ver e ser. Quando se está a ver, não se pode estar a ser. Ver a vida implica distanciar-se dela, falhar sê-la. A categoria do tempo não parece resolver este problema, nem parece enunciá-lo, pois o tempo não diz tanto respeito ao ver, à fixação visível, delimitável e descontínua inerente a qualquer visão, como à percepção do movimento, da passagem, à contagem do ritmo que é mais própria do ouvir. O ouvido tem, provavelmente, mais afinidades com o sentido interno que percebe a passagem do tempo do que os olhos voltados e votados à exterioridade, à espacialidade.

É interessante notar que na obra de Pessoa, tão marcada pelo movimento (pelas metamorfoses, a velocidade, a ideia de viagem, de deambulação interior e exterior) as referências ao ouvir sejam parcas. Campos é a excepção, a sua atenção aos sons e ruídos fá-lo absorvê-los em si e nos seus versos (que não só os descrevem, como os repetem). E assim também parece digna de nota a diminuta presença de referências à música, arte do tempo, nos textos pessoanos. Esta não está, porém, ausente, e uma atenção às suas ocorrências mostraria, pelo menos, duas coisas: que a música aparece ligada à noite, e que a música se liga com a infância. Pense-se em Chuva oblíqua, em que a música lembra ao poeta um dia da infância em que brincava atirando uma bola ao muro do quintal: "a minha infância/ Está em todos os lugares, e a bola vem a tocar música/ [...] E a música atira com bolas/ À minha infância...” (PESSOA, 1992, p. 31) ou na já referida ode à noite da Passagem das horas. E ainda Campos: "A música, sim, a música.../ [...] Aquilo que vem buscar o choro imanente/ De toda a criatura humana,/ Com o desejo de uma calma melhor... [...] Ah, quantas infâncias tive!/ Quantas boas mágoas!/ Sempre a música..." (CAMPOS, 2002, p. 501). Ora, o que é decisivo nestes exemplos em que a música é evocadora da infância é o facto de nessa evocação não se tratar propriamente de uma recordação de tempos passados, ou do tempo mítico da origem do sujeito. Tal como defendemos em relação ao infinito nocturno, também aqui não se trata de regressar a uma unidade originária. A música não 
evoca tanto como suscita o estado da infância, o qual, aliás, não é também ele uno. O poeta diz que a sua infância está em todos os lugares, que teve muitas infâncias e isso deve ser levado à letra. $\mathrm{O}$ que isso significa é que a infância não se situa num tempo cronológico obrigado à lógica da sucessão, mas que é um estado em que o tempo se transforma em espaço, numa simultaneidade disponível em qualquer momento do tempo (GIL, 1999, p. 83-95). Em Pessoa, a infância é uma construção, é um estado que pode ser suscitado por estratégias que o próprio poeta descreve (nomeadamente, no Livro do desassossego) e que implica a "desaprendizagem" descrita por Alberto Caeiro, que não cuida das categorias do tempo e do espaço, e para quem o ver tem primazia sobre o ouvir: "Sou fácil de definir./ Vi como um danado./ [...] Mesmo ouvir nunca foi para mim senão um acompanhamento de ver" (CAEIRO, 2001, p. 110). Em Caeiro não se trata da construção de um conhecimento do mundo (como em Fausto), mas do seu contrário, de "raspar a tinta com que me pintaram os sentidos,/ Desencaixotar as minhas emoções verdadeiras", um esforço de desaprender a tendência para a categorização, para a abstracção, que enformou o olhar dos modernos até o exilar do objecto olhado, deixando-lhe as mãos cheias dos seus próprios esquemas espácio-temporais e causais.

O essencial é saber ver, S Saber ver sem estar a pensar,/ Saber ver quando se vê,/ E nem pensar quando se vê/ Nem ver quando se pensa./ Mas isso (tristes de nós que trazemos a alma vestida!)/ Isso exige um estudo profundo,/ Uma aprendizagem de desaprender (CAEIRO, 2001, p. 58).

Caeiro não é um moderno. Em bom rigor, ele não se enquadra num contexto histórico, está fora da história, dada a sua peculiar relação com o tempo cronológico. É isso que explica a sua afinidade com a infância, que é o momento da vida que está fora de todas as idades e no qual a plasticidade da alma apresenta a sua potência máxima, o poder ser qualquer coisa, o conseguir pôr-se no lugar de qualquer coisa, o ser tudo de todas as maneiras em feliz desassossego. A criança brinca a ser várias personagens para experimentar o que lhe convém, para saber o que pode fazer durar, o que pode construir, misturando tempos diferentes num tempo plástico. Bernardo Soares chama a esta capacidade experimental "a arte de irrealizar" que caracteriza a infância e a que ele próprio aspira:

A criança sabe que a boneca não é real, e trata-a como real até chorá-la e se desgostar quando se parte. A arte da criança é a de irrealizar. Bendita essa 
idade da vida [...] quando se nega a realidade por brincar, tomando como reais as coisas que o não são! Que eu seja volvido em criança e o fique sempre, sem que me importem os valores que os homens dão às coisas nem as relações que os homens estabelecem entre elas (PESSOA, 1990-1991, p. 118 , v. I).

No Livro do desassossego, esta arte chama-se "jeito para sonhar", e tem a ver com o alcançar uma objectividade onde a alma não projecta nas coisas o seu interior, mas vê realmente o objecto despojado de todo o aparelho categorial da subjectividade, alcançando uma "objectividade absoluta". Neste sentido, os sonhos de Soares não são fugas à realidade, negações da vida (tal como as preces de Campos à noite ou a "formidável infância" de Caeiro), mas uma mudança de estado (de vida) que só a multiplicação anímica permite:

$\mathrm{O}$ processo que arranca para uma realidade mais que real um aspecto do mundo ou uma figura de sonho, arranca também para mais que real uma emoção ou um pensamento [...] Repare-se que a minha objectividade é absoluta, a mais absoluta de todas. Eu crio o objecto absoluto, com qualidades de absoluto no seu concreto. Eu não fugi à vida propriamente, no sentido de procurar para a minha alma uma cama mais suave, apenas mudei de vida e encontrei nos meus sonhos a mesma objectividade que encontrava na vida. [...] sou como alguém que visse passar na rua muita gente e simultaneamente sentisse de dentro as almas de todos [...] (PESSOA, 1990-1991, p. 98 , v. I).

Os sonhos de Soares são viagens nunca feitas, quer dizer, são movimentos da alma que superam o espaço e o tempo, alargando-os, descobrindo novas possibilidades que prevertem as categorias da subjectividade moderna tempo, espaço, sucessão, quantidade, interior, exterior, real, possível -, e se exprimem em"melodias de forma", numa "arte outra do que toda a arte", 8 que não é fruto de quietude, uniformidade, permanência, mas de viagens, travessias de intensidades e velocidades diferentes das que tecem a vida quotidiana:

Viajei. Julgo inútil explicar-vos que não levei nem meses, nem dias, nem outra quantidade qualquer de qualquer medida de tempo a viajar. Viajei no tempo, é certo, mas não do lado de cá do tempo, onde o contamos por

8 PESSOA, 1990-1991, p. 73, v. I. 
horas, dias e meses; foi do outro lado do tempo que eu viajei, onde o tempo não se conta por medida. Decorre, mas sem que seja possível medi-lo. É como que mais rápido que o tempo que vimos viver-nos (PESSOA, 1990-1991, p. 78 , v. I).

\section{"Mudar de alma. Como? Descobre-o tu"}

Todo o Livro do desassossego descreve tentativas de impregnação da consciência pelo exterior, paisagens interiores obtidas em viagens nunca feitas. "Viajar? Para viajar basta existir. [...] Só a fraqueza extrema da imaginação justifica que se tenha de deslocar para sentir. [...] A vida é o que fazemos dela. As viagens são os viajantes" (PESSOA, 1990-1991, p. 37, v II). O desassossego é, assim, a atenção permanente, o interesse constante por tudo de uma alma móvel, capaz de multiplicidade (lembremos Campos: "Mas o que importa é que não tenho calma" ou o ortónimo "Quem tem alma não tem calma" ${ }^{10}$ ). Em Álvaro de Campos, o desassossego chama-se "sentir tudo de todas as maneiras", uma modalidade de simpatia universal que exige, também ela, uma transformação do espaço em tempo, uma perversão das categorias da subjectividade pela intensificação de uma experiência que atravessa todos os tempos e todos os espaços num único momento:

Sentir tudo de todas as maneiras,/ Viver tudo de todos os lados,/ Ser a mesma coisa de todos os modos possíveis ao mesmo tempo,/ Realizar em si a humanidade de todos os momentos/ Num só momento difuso, profuso, completo e longínquo./ Eu quero ser sempre aquilo com que simpatizo,/ Eu torno-me sempre, mais tarde ou mais cedo,/ Aquilo com quem simpatizo, seja uma pedra ou uma ânsia,/ Seja uma flor ou uma ideia abstracta,/ Seja uma multidão ou um modo de compreender Deus./ E eu simpatizo com tudo, vivo de tudo em tudo (CAMPOS, 2002, p. 196).

Apesar do seu cansaço, o engenheiro afirma: "E contudo eu estou como ninguém/ De amoroso acordo com isto tudo...”. Este acordo não é uma pacificação, uma harmonia feliz e prolongada, mas resulta de um exercício, de uma disciplina anímica de que o "laboratório poético" (GIL, 1988, p. 9-28)

9 CAMPOS (2002, p. 69)

${ }^{10} \operatorname{PESSOA}(1993$, p. 48) 
pessoano é um exemplo máximo, e no qual são levadas a cabo experiênciaslimite de outramento e despersonalização, experiências de um sujeito que se multiplica, e observa e anota rigorosamente a desestruturação da sua consciência. Semelhante exercício poético, que é um exercício amoroso, de um desejo forte e da procura de novas sensações, é fundamentalmente visual, e dele resulta uma modalidade única de autoconhecimento, cuja "nitidez" faz conhecer toda a humanidade: "O hábito único de sonhar deu-me uma extraordinária nitidez de visão interior. [...] Por isso conheço-me inteiramente, e, através de conhecer-me inteiramente, conheço inteiramente a humanidade toda. [...] para mim, sonhar é possuir" (PESSOA, 1990-1991, p. 97, v. I).

Não se trata, portanto, de um conhecimento cumulativo, extensivo, quantitativo, mas de experimentar, sentir intensamente "apenas as sensações mínimas e de coisas pequeníssimas”, a paisagem chinesa da chávena de chá, o céu negro ao fundo do sul do Tejo, as mãos cabeludas do patrão Vasques:

Tudo em mim é a tendência para ser a seguir outra coisa: uma impaciência da alma consigo mesma, como com uma criança inoportuna; um desassossego sempre crescente e sempre igual. Tudo me interessa e nada me prende. Atendo a tudo sonhando sempre; fixo os mínimos gestos faciais de com quem falo, recolho as entoações milimétricas dos seus dizeres [...] (PESSOA, 1990-1991, p. 39, v. II).

A minúcia da atenção desta estratégia de microscopia leva aos seus limites a temporalidade, despedindo a sucessão e as noções de passado e futuro, e também a dicotomia entre o real e o possível, tornando acessível uma experiência que triunfa de toda a realidade:

Tenho a impressão de que conheci horas de todas as cores, amores de todos os sabores, ânsias de todos os tamanhos. Desmedi-me pela vida fora, e nunca me bastei nem me sonhei bastando-me [...] o cansaço de ter tido um passado, o tédio de viver o presente, e o desassossego de ter que ter um futuro. Mas tanto me esforço que fico todo no presente matando dentro de mim o passado e o futuro. [...] De modo que desligo de mim como aos dois braços de um amplexo, os dois grandes tédios que me apertam - o tédio de poder viver só o Real, e o tédio de poder conceber só o possível. Triunfo assim de toda a realidade (PESSOA, 1990-1991, p. 80, v. I).

Isto supõe concentração, atenção, intensificação, que em Soares é um primordial "hábito e jeito para sonhar", e "sonhar é encontrarmo- 
nos", ${ }^{11}$ é ser o Colombo da nossa alma, um deixar-se possuir por si próprio, para o qual é preciso não tocar na vida "nem com a ponta dos dedos": "A (minha) vida é como se me batessem com ela". A "minha" vida é o que me impede de alcançar "a" vida, é a fixação de um sujeito num espaço e num tempo determinados que impede o movimento livre da alma, a inocência sem história que lhe permite ser todas as histórias, a inconsciência plástica que é própria das crianças. Ser ninguém é ser sempre um outro, ser uma pessoa, uma coisa qualquer, poder de ser todas as coisas, desassossego inocente: "Tu não ages: és agido; tu não vives: és vivido apenas". Para aprender isto não basta não ser cego, "é preciso também não ter filosofia nenhuma" (CAEIRO, 2001, p. 174). É na desaprendizagem das categorias filosóficas e abstractas que separaram as coisas da sua concretude, é na sua transformação em "inconceitos" que consiste o segredo da alegria de Caeiro, e os seus versos transmitem-na ao leitor, rasgando "os trapos do fato conceptual" que o separa do mundo e de si próprio. É o discípulo Campos quem diz que ler o mestre "é uma brisa", e lhe traz fé "na pequenez transcendente da vida", porque Caeiro "vitaliza" com outra coisa diferente de ideias: "é o poeta Caeiro, não o filósofo Caeiro que nos ama. O que recebemos daqueles versos é a sensação infantil da vida" (CAMPOS, 1997, p. 84). Caeiro ensina a amar a vida, porque o mestre não vê para dentro, para ele pensar é sentir, compreender é compreender com os olhos. Não haver cisão entre pensamento e sensação é a indicação da possibilidade poética de se encontrar a si próprio e construir uma alma nova que conceda novas sensações:

A única maneira de teres sensações novas é construires-te uma alma nova. [...] as coisas são como nós as sentimos [...] e o único modo de haver coisas novas é haver novidade no senti-las. Mudar de alma. Como? Descobre-o tu (PESSOA, 1990-1991, p. 93, v. I).

Pessoa descobriu-o, certamente, a sua obra prova-o tanto como exprime a dificuldade da tarefa. Multiplicar-se foi a sua forma de conhecer a continuidade entre pensar e sentir, e de experimentar "a minha coexistência com o mundo". A escrita pessoana é uma prova de amor pela concretude, pela sensualidade - "Gosto de dizer. Direi melhor: gosto de palavrar. As palavras são para mim corpos tocáveis, sereias visíveis, sensualidades incorporadas" (PESSOA, 1990-1991, p. 196, v. II) - e uma arte outra do que toda a arte,

${ }^{11}$ PESSOA, 1990-1991, p. 88, v. I. 
diferente, em particular, da arte de pensar, em que a análise das sensações e do visto não traz o desconforto da descontinuidade, da separação, da transcendência de tudo a tudo: "Jazo a vida. Nada de mim interrompe nada" (PESSOA, 1990-1991, p. 96, v. I).

\section{Referências}

CAEIRO, A. Poesia. Lisboa: Assírio e Alvim, 2001.

CAMPOS, Á. de. Notas para a recordação do meu mestre Caeiro. Lisboa: Editorial Estampa, 1997.

CAMPOS, Á. de. Poesia. Lisboa: Assírio e Alvim, 2002.

GIL, J. Fernando Pessoa ou a metafísica das sensações. Lisboa: Relógio d'Água, 1988.

GIL, J. O espaço interior. Lisboa: Editorial Presença, 1993.

GIL, J. Diferença e negação na poesia de Fernando Pessoa. Lisboa: Relógio d’Água, 1999.

LOURENÇO, E. Poesia e metafísica. Lisboa: Gradiva, 2002.

PESSOA, F. Fausto. Tragédia subjectiva (Fragmentos). Lisboa: Editorial Presença, 1988.

PESSOA, F. Livro do desassossego. Lisboa: Editorial Presença, 1990-1991. v. 2. Editorial Teresa Sobral Cunha.

PESSOA, F. Poesias. Lisboa: Edições Ática, 1992.

PESSOA, F. Novas poesias inéditas. Lisboa: Edições Ática, 1993.

Recebido:20/08/2010

Received: 08/20/2010

Aprovado: 28/09/2010

Approved: 09/28/2010 